\title{
Physiology of the haunted mind: Naturalistic theories of apparitions in early nineteenth- century Scotland
}

Bill Jenkins

\begin{abstract}
The late eighteenth and early nineteenth centuries saw a resurgence of interest in the supernatural in Scotland as elsewhere in the United Kingdom. A number of intellectual figures responded by proposing naturalistic explanations for supernatural phenomena, drawing on the legacy of Scottish Enlightenment philosophy. These included the geologist and antiquarian Samuel Hibbert and the phrenologist George Combe. This paper explores the interrelations between these theories, their roots in the troubled cultural politics of Scotland in the early nineteenth century and the reaction of different protagonists in the cultural conflicts of the period to their ideas.
\end{abstract}

\section{Introduction}

On 26 October 1830 Mrs A. observed a strange coach approaching the gates of her house. As it drew closer she was shocked to see "the figures of the postillions and the persons inside take the ghastly appearance of skeletons and other hideous figures." ${ }^{\prime 1}$ However, as the natural philosopher David Brewster (1781-1868) recounts in his Letters on Natural Magic, she was not unduly alarmed by this bizarre turn of events, for she had read Sketches of the Philosophy of Apparitions

I would like to thank Clare Button, Felicity Loughlin and Catherine Laing who read and commented on earlier drafts of this paper. My thanks are also due to the two anonymous referees for the Journal of the History of Ideas. This paper is very much improved as a result of their constructive comments and suggestions.

${ }^{1}$ David Brewster, Letters on Natural Magic Addressed to Sir Walter Scott (London: John Murray, 1832), 45. 
by Samuel Hibbert (1782-1848), and was therefore "fully aware of the delusive nature of the apparition.",2

While belief in ghosts and other supernatural visitations has been a constant of human culture in all eras, by the end of the eighteenth century it was widely considered a relic of the ignorant and superstitious past by members of Scotland's intellectual elite. Nonetheless, the early decades of the nineteenth century witnessed a growing fascination with the supernatural that coincided both with the heyday of the Scottish Gothic in literature and the growing influence of evangelicalism in Scottish society. These developments inspired a number of theories that claimed to lay the ghosts to rest by explaining apparitions in naturalistic terms. The connections between Scottish Gothic literature and contemporary medical and phrenological doctrines have already been admirably elucidated by Megan Coyer. ${ }^{3}$ In this paper I will focus instead on how naturalistic explanations of apparitions drew on the theories of mind of the Scottish Common Sense philosophers and their heirs, focusing in particular on the far-reaching influence of Thomas Brown (1778-1820), professor of moral philosophy at the University of Edinburgh from 1810 until 1820. Situating the discourse on apparitions within the contested terrain of postEnlightenment Scottish culture, I will show how these theories, irrigated by the well-springs of late-Enlightenment rationalism, represented an attempt to re-assert the power of human reason to

\footnotetext{
${ }^{2}$ Brewster, Letters on Natural Magic, 44. Mrs A was in fact Richarda Airy, the wife of the well-known astronomer George Airy. See Louise Henson, 'Investigations and fictions: Charles Dickens and Ghosts,' in Nicola Brown, Carolyn Burdett and Pamela Thurschwell (eds), The Victorian Supernatural (Cambridge: Cambridge University Press), 44-64, p. 47. My tthanks are due to Daniel Belteki for drawing this to my attention. ${ }^{3}$ See in particular Megan Coyer, "The phrenological dreamer: The popular medical and fictional writing of Robert Manish (1802-1837)," in The Apothecary's Chest: Magic, Art and Medication, ed. Konstantina Georganta, Fabienne Collignon and Anne-Marie Millim (Newcastle upon Tyne: Cambridge Scholars Publishing, 2009), 1-11; Megan Coyer, "The Embodied Damnation of James Hogg's Justified Sinner," Journal of Literature and Science 7:1 (2014): 1-19; and Megan Joann Coyer, "The Ettrick Shepherd and the Modern Pythagorean: science and imagination in romantic Scotland," PhD thesis, University of Glasgow (2010).
} 
explain the supernatural in the febrile atmosphere of Scotland in the decades following the French Revolution.

Intellectual life in Scotland in the late eighteenth century had been dominated by a group of philosophers and historians associated with the Moderate Party of the Church of Scotland, whose students and disciples still presided over Scottish intellectual circles in the early decades of the nineteenth century. ${ }^{4}$ In this paper I will describe these individuals collectively as the "moderate literati," using initial capitals for "Moderates" and "Evangelicals" only when referring to the respective parties within the Church of Scotland. I will use this term principally to refer to the literary and philosophical circles around Sir Walter Scott (1771-1832). It is intended to reflect a general intellectual outlook rather than formal allegiance to any religious or political party.

David Brewster, for example, was a staunch supporter of the Evangelical Party and later an elder of the Free Kirk; however, when it came to the question of apparitions, he favored a naturalistic explanation over a supernatural one. ${ }^{5}$ While it may seem self-contradictory to describe Brewster as an "moderate Evangelical", this in fact gives a fair sense of his philosophical outlook. While many of the moderate literati did not belong to the Moderate Party, and may even, like Brewster, have been Evangelicals, they did generally share the broadly secular philosophical perspectives of the Moderate literati of the previous century. Like them, they wrote their philosophical and historical works without explicit reference to Scripture or Christian doctrine. That their writings were secular does not imply that they were deists or atheists. On the contrary, most of them were orthodox Christians who simply kept their religious views separate from their historical or

\footnotetext{
${ }^{4}$ Richard B Sher, Church and University in the Scottish Enlightenment: The Moderate Literati of Edinburgh (Edinburgh: Edinburgh University Press, 2015).

${ }^{5}$ For an insightful account of the thought of Brewster and his fellow scientific Evangelicals, see Paul Baxter, 'Science and Belief in Scotland, 1805-1868: The Scottish Evangelicals,' PhD thesis, University of Edinburgh (1985).
} 
philosophical writings. However, the secular, deistic tone of their works drew a strong reaction from many of their Evangelical contemporaries. As the Scottish Evangelical journalist and geologist Hugh Miller (1804-56) wrote in the 1840s, the neglect of Scripture in the writings of the Moderates of the previous generation suggested that they regarded Christianity as nothing but "an idle and unsightly excrescence on a code of morals that would be perfect were it away."6 While some notable historians have suggested that intellectual debates in early nineteenthcentury Edinburgh were largely animated by class antagonism, I would argue that, at least as far the debate on apparitions is concerned, the real fault lines were confessional, not political. ${ }^{7}$ On the side of naturalistic explanation stood both Tories, such as Walter Scott, and Whigs, such as Samuel Hibbert, while their opponents were drawn principally from the more hardline among the city's evangelicals.

The world that the moderate literati of the early nineteenth century inhabited had changed profoundly since the days of their eighteenth-century forebears. The French Revolution, its bloody aftermath and the radicalism it inspired at home had led to a collapse of faith in the Enlightenment project. Events on the continent had a profound impact in Edinburgh. In his autobiography Henry Cockburn (1779-1854) wrote that: "Every thing rung, and was connected, with the Revolution in France; which for above 20 years, was, or was made, the all in all." 8 The faltering of confidence in the power of reason and progress ushered in an era of anxiety which led many to fall back on tradition and authority, while others sought certainty in resurgent

\footnotetext{
${ }^{6}$ Hugh Miller, Foot-Prints of the Creator: or. the Asterolepis of Stromness (London: Johnstone and Hunter, 1849), 17.

${ }^{7}$ See in particular Adrian Desmond, The Politics of Evolution: Morphology, Medicine and Reform in Radical London (Chicago: University of Chicago Press, 1989); Steven Shapin, "Phrenological knowledge and the social structure of early nineteenth-century Edinburgh," Annals of Science 3 (1975): 219-43; and Roger Cooter, The Cultural Meaning of Popular Science: Phrenology and the Organization of Consent in Nineteenth-Century Britain (Cambridge: Cambridge University Press, 1984).

${ }^{8}$ Henry Cockburn, Memorials of His Time (Edinburgh: Adam and Charles Black, 1856), 80.
} 
evangelicalism. The God of the Evangelicals was more inclined than that of the Moderates to intervene directly in the world through supernatural agency, and to allow other supernatural agents, whether angelic or demonic, to manifest themselves in the world. Thomas Chalmers, the charismatic leader of the Evangelical Party, for example, devoted several pages of his famous Discourses on Christian Revelation Viewed in Connection with Modern Astronomy (1817) to speculations on the benevolent intervention of angels. ${ }^{9}$ It could therefore not be taken for granted that all phenomena were amenable to human reason in a law-governed universe. Nonetheless, the heirs of the Scottish Enlightenment clung to their faith in the power of reason and defended it whenever possible. The debate on the nature of apparition took place against the background of this dramatic cultural shift. They strove to reassert the universal power of human reason in domains that did not leave them open to accusations of atheism or radical political sympathies. Belief in ghosts could be presented as a superstition of the ignorant masses or a phenomenon of the dark days of religious extremism before the Union. It was therefore a relatively safe target on which to demonstrate the power of reason. It was also an especially attractive topic at this time, as the subject had been rendered topical by the Romantic fascination with all things weird and unearthly, itself a symptom of the general crisis of faith in a benign natural order. In Scotland this fascination with the supernatural took the form of a distinctive style of Gothic literature. Before turning to examine the naturalistic assault on the supernatural, I will therefore briefly review its the place in contemporary Scottish literary culture.

\footnotetext{
${ }^{9}$ Chalmers, Thomas, A Series of Discourses on the Christian Revelation, Viewed in Connection with the Modern Astronony (Glasgow: John Smith and Son, 1817), 177-9. For an analysis of Chalmers's views on science and religion, see Jonathan R. Topham, 'Science, natural theology, and evangelicalism in early nineteenth-century Scotland: Thomas Chalmers and the Evidence controversy,' in Evangelicals and Science in Historical Perspective, ed. David N. Livingstone, D. G. Hart and Mark A. Noll (New York, NY: Oxford University Press, 1999), 142-74.
} 


\section{The supernatural in early nineteenth-century Scottish literary culture}

In the last decades of the eighteenth century and the early decades of the nineteenth a flood of literary works dealing with the mysterious and the supernatural fueled a craze for all things weird and otherworldly. Scotland produced its own native brand of Gothic, rooted in Scottish culture and history. Ian Duncan has defined "Scottish Gothic" as "a distinctive Scottish tradition of romantic fiction in prose and verse that originates in James Macpherson's Ossianic poetry in the 1760s and culminates in the work of Scott, James Hogg, and the contributors to Blackwood's Edinburgh Magazine in the 1820s." "10 The poems of Ossian were a remarkable corpus of poetic works, supposedly discovered and translated from ancient Gaelic sources by James Macpherson (1736-96). ${ }^{11}$ It is hard to over-emphasize the influence of these works on the late eighteenth- and early nineteenth-century imagination. The poems are replete with Celtic heroes communing with the ghosts of their ancestors against the sublime backdrop of misty mountains and raging cataracts in a mythic landscape where "Spirits ride on beams of fire." 12 Macpherson set his tales in the dim and distant Celtic past and later contributors to the genre would continue to opt for historical settings. This helped to distance the supernatural terrors they described from the enlightened present of post-Union Scotland. For Duncan, the Scottish Gothic represents “a wholesale temporal distinction between Scottish modernity - the habitus of the middle-class literary subject - and a category of cultural otherness designated as pre-modern." 13 Coyer has also written eloquently of "the struggle of Scottish Romantic writers to reconcile the continuing

\footnotetext{
${ }^{10}$ Ian Duncan, "Walter Scott, James Hogg, and Scottish Gothic," in David Punter, A New Companion to the Gothic (Oxford: Blackwell, 2002), 123-34, 123.

${ }^{11}$ For more on the poems of Ossian and their author see Fiona J Stafford, The Sublime Savage: A Study of James Macpherson and the Poems of Ossian (Edinburgh: Edinburgh University Press, 1988) and Derick S Thomson, "James Macpherson - the Gaelic dimension," in From Gaelic to Romantic: Ossianic Translations, ed. Fiona Stafford and Howard Gaskill (Amsterdam, 1998), 17-26.

12 James Macpherson, The Poems of Ossian and Related Works (Edinburgh: Edinburgh University Press, 1996$), 87$.

${ }^{13}$ Duncan, "Walter Scott, James Hogg, and Scottish Gothic," 124.
} 
drive towards rationalism and scientific progress, as fueled by the Scottish Enlightenment of the eighteenth-century, and their desire for poetic inspiration."14 The Scottish Gothic writers therefore wanted to have their supernatural cake and eat it, by allowing their readers the sublime thrill of the unknown and mysterious while denying its relevance to the modern, enlightened world of their own time.

A favorite setting for authors such as Scott and James Hogg (1770-1835) was the Scotland of the seventeenth century, often portrayed as a dark period of savage intolerance, fierce religious enthusiasm and rampant superstition, contrasting with the reason and moderation of the present. ${ }^{15}$ Scott's early work is steeped in Scottish Gothic themes, and he was deeply influenced by his reading of supernatural stories in his youth; as he himself admitted in his Letters on Demonology and Witchcraft (1830), "it is no doubt true that I travelled a good deal in the twilight regions of superstitious disquisitions."16 The house journal of the Scottish Gothic was Blackwood's Edinburgh Magazine. Conceived as a Tory alternative to the Whig Edinburgh Review, in the words of Duncan, "Blackwood's assembled, in short, the cultural repertoire of a modern Gothic counter-Enlightenment, the source of an 'organic' nationalist spirituality and sentiment."17 That the Blackwood's circle were enamored of the weird and the supernatural is undeniable. I would, however, question Duncan's designation of them as 'anti-Enlightenment,' and would see them not as champions of irrationalism and the superstition, but rather as representing a conservative strand of late-Enlightenment thought. It is worth noting that the

\footnotetext{
${ }^{14}$ Coyer, "Phrenological dreamer," 9.

${ }^{15}$ In a thought-provoking article Ina Ferris has suggested that Scott's historical fiction presented a vision of the past that was essentially “apparitional.” See Ina Ferris, “'Before Our Eyes:' Romantic Historical Fiction and the Apparitions of Reading,' Representations 121:1 (2013): 60-84.

${ }^{16}$ Walter Scott, Letters on Demonology and Witchcraft Addressed to J.G. Lockhart, Esq (London: John Murray, 1830), 2.

${ }^{17}$ Duncan, "Walter Scott, James Hogg, and Scottish Gothic," 132.
} 
supernatural events they described were most often provided with a safely rational explanation in the end, as Hogg does in his The Brownie of Bodsbeck (1818). Elsewhere Duncan has commented that "Enlightenment natural historicism relies on schemes of developmental continuity" while "the uncanny is the subjective figure of a violent discontinuity at the transition between historical orders."18 This sense of rupture in historical consciousness could be dissipated through the naturalistic explanation of the supernatural. The task set himself by Hibbert and his fellow philosophers of apparitions was to exorcise this apparent rupture by establishing once and for all the explicability of apparitions. In an age still overshadowed by the threat of violent social disruption, arguments for the continuity of a rational natural order had obvious appeal to the heirs of the Scottish Enlightenment.

Hogg had a more ambiguous relationship with the supernatural than Scott and in his best-known work, The Private Memoirs and Confessions of a Justified Sinner (1824), he refused to provide the expected rational explanation of the supernatural events he described. Megan Coyer has written in this regard that "it would be easy to read the unaccountability of the Confessions as a critical subversion of the physiological 'explained supernatural' of the Romantic period."19 It is perhaps for this reason that Hogg could be portrayed as an antagonist to the advocates of naturalistic explanations of apparitions, as I will explore in the next section.

\section{Apparitions and the moderate literati of Edinburgh}

\footnotetext{
${ }^{18}$ Ian Duncan, Scott's Shadow: The Novel in Romantic Edinburgh (Princeton, HJ: Princeton University Press, 2007), 186.

${ }^{19}$ Coyer, "Embodied Damnation," 2. Michelle Faubert has attempted to explain Hogg's refusal to neatly tie up his story with a natural explanation as inspired by the writings of John Ferriar; see Michelle Faubert, "John Ferriar's psychology, James Hogg's Justified Sinner, and the gay science of horror writing," in Thomas H. Schmid and Michelle Faubert, Romanticism and Pleasure (New York, NY, Palgrave Macmillan, 2010).
} 
A number of notable figures from among the Scottish moderate literati put forward theories regarding the true nature of apparitions during the 1820s and 1830s. Hibbert's Sketches of the Philosophy of Apparitions was perhaps the most influential of these. Originally from a mercantile family in Manchester, Hibbert had come to Edinburgh in 1817 to study medicine and rapidly fell in with the Edinburgh literary circle around Scott. It was Scott himself who suggested the idea of the book to Hibbert after hearing him give a paper on the same subject to the Royal Society of Edinburgh in the winter of $1823 .^{20}$ Hibbert acknowledged the debt by dedicating the work to Scott. The book seems to have been well received in Edinburgh literary circles. In 1825 it was even made the subject of a humorous fictional dialogue between "Christopher North" (a pseudonym for the writer John Wilson (1785-1854)) and a "Shepherd" (a thinly disguised caricature of the "Ettrick Shepherd,' James Hogg), in the long-running series "Noctes Ambrosianae," which appeared in the home of the Scottish Gothic, Blackwood's Magazine. ${ }^{21}$ Here "North" lectured Hogg on the merits of Hibbert's book and mocks him for his own credulous belief in ghosts.

As North points out to the "Shepherd," Hibbert's theory of apparitions was profoundly influenced by the theory of mind of Thomas Brown, whose lectures Hibbert had attended as an undergraduate. These lectures, published posthumously in 1820, became one of the most successful and influential philosophical works of the period. ${ }^{22}$ Hibbert adopted the Brownian theory of the mind in its entirety. Like Hibbert, Brown had studied medicine at the University of Edinburgh and had a strong interest in physiological as well as metaphysical perspectives on the

\footnotetext{
${ }^{20}$ Margaret Maria Gordon, The Life and Correspondence of the Late Samuel Hibbert Ware (Manchester, 1882), 316.

${ }^{21}$ [John Wilson], "Noctes Ambrosianae, No.XIX," Blackwood's Magazine 17:98 (1825): 366-384.

22 Thomas Dixon, From Passions to Emotions: The Creation of a Secular Psychological Category (Cambridge: Cambridge University Press, 2003), 111.
} 
mind. He differed from the Common Sense philosophers Thomas Reid and Dugald Stewart in drawing heavily on the empiricist associationism of David Hume (1711-76). Thomas Dixon has rightly suggested that Brown can best be described as a "common sense sceptic," combining elements of the Common Sense philosophy of Reid with Humean skepticism. ${ }^{23}$ Following Reid, Brown saw the mind as a mysterious, indivisible monad, the "thinking principle," whose attributes could only be investigated through introspection. ${ }^{24}$ Although the ultimate nature of the mind was unknown, Reid had believed it was possible to identify "powers and faculties" possessed by the mind, at least some of which were innate and prior to all sense experience.

Philosophers working within the tradition of the Scottish Common Sense school espoused an essentially Cartesian view of the mind-body question, in that they posited a radical separation between the immaterial mind and the material body. For Brown the anatomical structure of the brain did not in any way reflect the organization of the mind, which could not be analyzed into component parts; "the mind is not composed of parts that coexist, but is simple and indivisible". ${ }^{25}$ Thoughts and feelings did not therefore reflect the operations of different faculties of the mind but were "nothing more than the mind itself existing at a certain moment in a certain state." 26 Like Hume, Brown totally rejected Reid's faculty psychology and "saw the mind [...] as a single chain of basic impressions and ideas." ${ }^{27}$ Faculties were replaced by different states of the indivisible mind. Hibbert grounded his theory of apparitions squarely in this model of the mind, which he had imbibed from the lectures of Brown. He wrote that:

\footnotetext{
${ }^{23}$ Dixon, From Passions to Emotions, 110-11.

24 Thomas Reid, An Inquiry into the Human Mind on the Principles of Common Sense (Edinburgh: Edinburgh University Press, 1997), 13.

25 Thomas Brown, Lectures on the Philosophy of the Human Mind (Andover: Mark Newman, 1822), 1:82.

${ }^{26}$ Brown, Lectures on the Philosophy of the Human Mind, 1:82.

${ }^{27}$ Dixon, From Passions to Emotions, 107.
} 
The essential view of the mind which I have adopted in preference to every other is that of the late much-lamented Professor of Moral Philosophy in the university of Edinburgh. Dr Brown, in considering the mind as simple and indivisible, conceives that every mental feeling is only the mind itself, existing in a certain state. ${ }^{28}$

Hibbert's book also drew heavily on An Essay Towards a Theory of Apparitions (1813) by the Scottish physician John Ferriar (1761-1815) for both elements of his theory and many of his examples. Hibbert was entirely at one with Ferriar's opinion that "a morbid disposition of the brain is capable of producing spectral impressions, without any external prototypes." ${ }^{29}$ He went much further than Ferriar in proposing a detailed physiological mechanism for the phenomenon. Hibbert identified the circulatory system as having a particular role to play: "blood may, from nothing more than the excess in which it prevails throughout the system, prove a stimulant capable of inducing an undue vividness of thought." 30 To support this proposition he gave the example of the Berlin bookseller, Christof Friedrich Nicolai (1733-1811), whose case was also cited by Ferriar. Here a course of bleeding appears to have been enough to banish the illusions from which Nicolai had suffered. ${ }^{31}$ Not only an excess of blood, but its quality, could result in the appearance of spectral illusions. Hibbert identified four specific causes that can influence the quality of the blood in this way:

the causes thus affecting the sanguineous system, may be considered as arising, in the first place, from hereditary or constitutional taints of the blood; 2dly, From the

\footnotetext{
${ }^{28}$ Hibbert, Philosophy of Apparitions, 62.

${ }^{29}$ Ferriar, John, An Essay Towards a Theory of Apparitions (London: Cadell and Davies, 1813), 99.

${ }^{30}$ Hibbert, Philosophy of Apparitions, 86.

${ }^{31}$ Hibbert, Philosophy of Apparitions, 89.
} 
suppression of the healthy or accustomed evacuations; 3dly, From adventitious matters directly admitted into the composition of the blood; and, 4thly, From circumstances affecting the state of the circulating system through the medium of the nerves or brain. ${ }^{32}$

Following Ferriar's lead he concluded that "apparitions are nothing more than ideas, or the recollected images of the mind, which have been rendered more vivid than actual impressions." 33 When the abnormal physiological state experienced by a person led to the images derived from the memory becoming more vivid and intense than actual sense impressions, that was when a person would experience an apparition. However, apparitions could not only be derived from real memories of people and events, but also from imagery drawn from literature and folklore, thus explaining the stereotypical nature of many accounts of ghosts and other supernatural visitations. Hibbert suggested that in normal mental states chains of associated ideas derived from memories of real or imagined people and events are constantly flowing through the mind, but we are not conscious of these because they are so faint. When "a morbific cause" renders them strong enough to be perceived, we are at a loss to see where they have come from and hence imagine that they are derived from an external source. ${ }^{34}$

For Hibbert the images presented to the mind had a concrete existence in the sense organs, as "past feelings are renovated through the medium of organs of sensation." 35 The image of an apparition was projected onto the retina of the viewer, reversing the normal process of sensation.

\footnotetext{
${ }^{32}$ Hibbert, Philosophy of Apparitions, 71.

${ }^{33}$ Hibbert, Philosophy of Apparitions, v.

${ }^{34}$ Hibbert, Philosophy of Apparitions, 128.

${ }^{35}$ Hibbert, Philosophy of Apparitions. 254.
} 
Hibbert called on the authority of his friend the natural philosopher David Brewster in support of this assertion. As Brewster had noted in a paper published in 1824:

When the eye is not exposed to the impressions of external objects, or when it is insensible to these impressions, in consequence of the mind being engrossed with its own operations, any object of mental contemplation which has either been called up by the memory, or created by the imagination, will be seen as distinctly as if it had been formed from the vision of a real object. ${ }^{36}$

Brewster concluded that "in the unhealthy condition of the mind, the impressions of its own creation either overpower, or combine themselves with the impressions of external objects." ${ }^{\prime 37}$ In his Letters on Natural Magic (1832) Brewster praised Hibbert's "admirable work," which had placed his naturalistic explanation of apparitions "beyond the reach of doubt." ${ }^{38} \mathrm{He}$ went on to further develop Hibbert's conjecture on the role of the sense organs in the phenomenon of apparitions, asserting that 'the 'mind's eye' is actually the body's eye, and that the retina is the common tablet on which both classes of impressions are painted, and by means of which they receive their visual existence according to the same optical laws." ${ }^{39}$

Scott was also full of praise for Hibbert's theory in his own Letters on Demonology, writing that he had "most ingeniously, as well as philosophically, handled this subject." ${ }^{40}$ While Scott broadly agreed with Hibbert's naturalistic explanation of apparitions, he was careful to leave

\footnotetext{
${ }^{36}$ David Brewster, "Observations on the vision of impressions on the retina in reference to certain supposed discoveries respecting vision announced by Mr. Charles Bell," Edinburgh Journal of Science 2 (1824): 1-9, 8.

${ }^{37}$ Brewster, "Observations on the vision of impressions," 9.

${ }^{38}$ Brewster, Letters on Natural Magic, 48-9.

${ }^{39}$ Brewster, Letters on Natural Magic, 49.

${ }^{40}$ Scott, Letters on Demonology, 22-3.
} 
open the possibility of miracles: "the philosopher may challenge the possibility of a separate appearance of a disembodied spirit, unless in the case of a direct miracle, to which, bring a suspension of the laws of nature, directly wrought by the Maker of these laws, for some express purpose, no bound or restraint can possibly be assigned." ${ }^{41}$ As we will see below, Hibbert's theory had aroused the wrath of some sections of Evangelical opinion, and Scott may have been attempting to head off criticism from that quarter.

\section{Phrenological explanations: Apparitions and the organ of Wonder}

Another group of heirs of Enlightenment rationalism who also took an interest in the phenomenon of apparitions were Edinburgh's phrenologists. George Combe (1788-1858) was Edinburgh's leading phrenologist and the most important advocate of the new would-be science in the English-speaking world. He was also the author of the enormously influential Constitution of Man (1828, and numerous subsequent editions). Combe too gave a naturalistic account of apparitions in his A System of Phrenology (1825). The Phrenological Journal and Miscellany, edited by Combes, also carried a string of articles on the subject. ${ }^{42}$ Steeped in the works of the Common Sense school, Combe saw in phrenology "what Reid, [Dugald] Stewart, Brown, and others had sought and failed to find." ${ }^{, 43}$ In a sense, he therefore saw himself as bringing their work to a triumphant conclusion. Although Combe's brand of phrenology clearly had roots in Scottish Enlightenment thought, it presented a challenge to the Brownian view of the nature of

\footnotetext{
${ }^{41}$ Scott, Letters on Demonology. 15-16.

${ }^{42}$ See Anon, “Apparitions," Phrenological Journal 2:5 (1824): 111-3; Anon, "Observations on spectral illusion, and other illusive perceptions of the knowing organs when in morbid excitement, illustrated by a recent case,"

Phrenological Journal 2:6 (1825): 290-308; “A case of spectral illusion," Phrenological Journal 5:18, 1828, 210-3; Anon, "Additional case of spectral illusion, with accompanying pain in the organs of form, size, weight, colouring, order, number and individuality," Phrenological Journal 5(18) (1828): 319-32; Anon, "Case of spectral illusions. To the editor of the Phrenological Journal," Phrenological Journal 7:28 (1832): 162-5.

${ }^{43}$ Charles Gibbon, Life of George Combe: Author of the "Constitution of Man" (London, Macmillan, 1878), 1, 163.
} 
the mind and its relationship with the body. Instead of relying on introspection as the key to understanding the human mind, the physical structure of the human brain could be interrogated for insights into the functioning of the mind. It owed its origin to the work of a Viennese doctor Franz Josef Gall (1758-1828) and his assistant Johann Gaspar Spurzheim (1776-1832). It was Spurzheim who did most to popularize phrenology in Britain, making a convert of Combe during a visit to Edinburgh.

Gall based his new science of the mind on three fundamental principles: the brain is the organ of the mind; the brain is composed of a collection of separate organs, each representing a "faculty" of the mind; and the size of the organ is proportional to the development of the associated faculty. Combe summarized this doctrine in his Elements of Phrenology the following words: "the brain is the material instrument by means of which the mind acts, and is acted upon; and it is a congeries of organs." $" 44$ The faculties that they claimed to have identified could be divided into those of feeling, such as Combativeness, Veneration and Wonder, and intellectual faculties, such as Form, Time and Comparison. Each faculty had its own identifiable organ in the brain. The character of the individual depended on the relative development of these different organs. On the assumption that the shape of the skull faithfully mirrored the form of the brain beneath, the character of a given individual could be "read" from the shape of their skull by a skilled practitioner. The wide appeal of phrenology is well expressed by Roger Cooter who remarks that “it transformed abstract metaphysical conceptions of mind into actual organic entities, amenable to the interests and understandings of the practical-minded." 45 Although, as Sherrie Lynn Lyons

\footnotetext{
${ }^{44}$ George Combe, Elements of Phrenology, 3rd edn (Edinburgh: John Anderson, 1828). 23.

${ }^{45}$ Cooter, The Cultural Meaning of Popular Science, 32.
} 
points out, in reality the classification of the faculties was never based on a process of induction, but rather on introspection and a priori assumptions, much as the faculties of Reid had been. ${ }^{46}$

Although G. N. Cantor has suggested that phrenology and common sense philosophy were incommensurable in a Kuhnian sense, Combe's version of phrenology did not necessarily contradict the Brownian view of the mind as an immaterial entity. ${ }^{47}$ Sensitive to accusations of materialism, Combe was quick to point out that phrenology did not concern itself with the materiality or otherwise of the mind itself, but only of the organs which compose the brain and act as instruments of the mind, the true nature of which remained a mystery: "We observe, therefore, as to the charge of Materialism, that, in this system, no inquiry is made into the nature either of the soul or of the body."48

Spurzheim had already raised the issue of apparitions in his The Physiognomical System of Drs Gall and Spurzheim, published in 1815. In this work he wrote: "We have observed that if the part of the head, above the organ of ideality and a little backward from it, be very much developed, the persons are disposed to mysticism, to have visions, to see ghosts, demons and phantoms[.." ${ }^{\prime 49}$ Combe developed Spurzheim's ideas at some length in his System of Phrenology. In the section of this book on the organ of Wonder, he asks: "How does it happen, that men of considerable intellect often believe in the reality of ghosts and visions? Are they fools, or impostors? or, Is

\footnotetext{
${ }^{46}$ Sherrie Lynn Lyons, Species, Serpents, Spirits, and Skulls: Science at the Margins in the Victorian Age (Albany, NY: State University of New York Press, 2009), 83-4.

${ }^{47}$ G.N. Cantor, "Phrenology in early nineteenth-century Edinburgh: An historiographical discussion," Annals of Science 32 (1975): 195-218.

${ }^{48}$ George Combe, Essays on Phrenology, or an Inquiry into the Principles and Utility of the System of Drs Gall and Spurzheim, and into Objections Made against It (Edinburgh: Bell and Bradfute, 1819), 98.

${ }^{49}$ Johann Gaspar Spurzheim, The Physiognomical System of Drs. Gall and Spurzheim: Founded on an Anatomical and Physiological Examination of the Nervous System in General, and of the Brain in Particular; and Indicating the Dispositions and Manifestations of the Mind (London: Baldwin Cradock, and Joy, 1815), 346.
} 
there a particular organization, which imposes, in this form, on the human understanding?" ${ }^{50}$ In answering these questions Combe was more definite than Spurzheim. For him, apparitions were the product of an overdeveloped organ of Wonder, which in turn excited other organs, such as Form and Colouring, to summon up vivid spectral illusions. Combe provided numerous case studies both from history and his own experience to prove the connection between a propensity to see apparitions and a highly developed organ of Wonder; for example, he recounted how "In London Bedlam, I examined the head of a patient whose insanity consisted in seeing phantoms [...] In him the organ of Form was well developed, and that of Wonder was decidedly large."51 Other organs could also be implicated, as "diseased excitement of the knowing organs produces spectral illusions, independently of an affection of the organ of Wonder." 52

In 1824 a review of Hibbert's Philosophy of Apparitions for the Phrenological Journal gave an essentially similar explanation, although with rather more physiological detail. This review was almost certainly also by Combe, as parts of it also appear verbatim in his System of Phrenology. In this review Combe stated that:

The organs may be excited by an unusual influx of blood into the vessels which supply them; by inflammation; or by nervous irritation. If the organs of Form, Colouring, and Size were stimulated into excessive activity, by any of these causes, the mind would be presented with the kind of conceptions which each of them, by its natural constitution, is

\footnotetext{
${ }^{50}$ George Combe, A System of Phrenology, 3rd edn (Edinburgh: John Anderson, 1825), 225.

${ }^{51}$ Combe, System of Phrenology, 235.

${ }^{52}$ Combe, System of Phrenology, 237.
} 
fitted to produce; or, in other words, Forms, invested with the attributes of Colour and Magnitude, would be presented involuntarily to the mind..$^{53}$

The circulatory system could therefore play a key role in overstimulating the organs responsible for the phenomenon. Only the functioning of the organs affected was altered; the person would otherwise appear perfectly lucid and rational. In Combe's opinion this provided strong proof of the truths of phrenology; if the mind was a single, indivisible entity, any derangement would affect all aspects of its operations. Once again the organ of Wonder is implicated in the production of apparitions; where this organ is very large there will be a tendency to see spectral illusions even in the absence of any pathological state. In such cases "Spectres, apparitions, spirits, \&c., are the kind of ideas suited to please an inordinate Wonder; and being congenial to the mind, the reality of such conceptions will meet with a ready belief." ${ }^{\prime 54}$

Hibbert and Combe had known each other for about five years when the Philosophy of Apparitions was published. They seem to have maintained cordial relations and Hibbert sent Combe a copy of his book on its publication, along with a letter outlining the areas where he was in agreement with the phrenologists, and where he differed from them. ${ }^{55}$ While not accepting the phrenologists' multiplicity of faculties, he admitted that he "agreed with the Phrenologists that every man comes into the world with decided innate dispositions." However, in the book itself he took a mischievous side-swipe at the phrenologists in a footnote where he stated: "Those droll philosophers, the Phrenologists, account for all this by supposing that Nicolai possessed the

\footnotetext{
${ }^{53}$ [George Combe], "Dr Hibbert on the Philosophy of Apparitions," The Phrenological Journal and Miscellany 1:4 (1824): 541-555, 547

${ }^{54}$ [Combe], "Dr Hibbert on the Philosophy of Apparitions," 553.

${ }^{55}$ Samuel Hibbert to George Combe, 9 March 1824 (National Library of Scotland MS.7213), 56-7.
} 
ORGAN OF WONDER." ${ }^{56}$ This slight did not go unnoticed. In a letter to Hibbert dated 13 March 1826, Sir George Mackenzie, both a friend of Hibbert and an enthusiastic supporter of phrenology, wrote "I know you like a cut at us, as you made one in your essay on Apparitions; but our knives will prove as sharp as yours. ${ }^{157}$ Combe himself acknowledged the copy of the book graciously in a letter to the author dated 18 March 1824, saying that he anticipated "both instruction and amusement" from reading it. He regretted that Hibbert's views had not come any closer to his own and acknowledged that "as this is not the case we must just exercise that liberality of judgement towards each other which becomes philosophers." ${ }^{\Perp 5}$

Despite the warm tone of his letter, Combe did not take long to get his knife into Hibbert's book, giving it a decidedly hostile review in the Phrenological Journal shortly after receiving the copy. In this review he first questions how a simple, unitary mind could be made to experience recollected images more vividly while the apparent vividness of current impressions remained unchanged: "If the blood be in the condition which vivifies recollected images to the height of actual impressions, how does it happen that it does not vivify the feelings, and the conceptions formed by the reflecting faculties to an equal or to any uncommon extent?"59 According to the phrenological theory, it can easily be argued that some organs are affected but not others due to their different positions and constitutions. Secondly, he goes on to argue that not all individuals who suffer from the physiological symptoms associated with apparitions actually experience them, demonstrating that another factor, such as the development of the relevant phrenological

${ }^{56}$ [Combe], "Dr Hibbert on the Philosophy of Apparitions," 128.

${ }^{57}$ Sir George Mackenzie to Samuel Hibbert, 13 March 1825, quoted in Hibbert Ware, Mrs, The Life and Correspondence of the Late Samuel Hibbert Ware (Manchester: J.E. Cornish, 1882), 354. The somewhat violent imagery of the letter was rather softened by Mackenzie good wishes for the health of Mrs Hibbert that immediately followed.

${ }^{58}$ George Combe to Hibbert, Samuel, 18 March 1824 (University of Manchester Special Collections, John Rylands Library, Eng. MS. 997, 10), 1.

${ }^{59}$ [Combe], "Dr Hibbert on the Philosophy of Apparitions," 549. 
organs, is necessary. Finally, he asserted that Hibbert's theory could not explain the cases where individuals had seen apparitions in the absence of any altered physiological state. Combe concluded that while Hibbert's book "has been cried up in periodical journals as a masterpiece of learning" he has "rarely seen a work intended for a theory or philosophical elucidation of phenomena, more defective in principle and consistency." ${ }^{\circ 0}$ Nonetheless, the hostility of Combe's review masks the many similarities between these two competing naturalistic theories of apparitions, a kinship that may go some way towards explaining the strength of Combe's reaction to a theory that was so close a rival to his own.

The phrenologist and physician Robert Macnish (1802-37) went some way to reconciling the theories of Hibbert and Combe in the second edition of his The Philosophy of Sleep (1834). ${ }^{61}$ Here Macnish made much greater use of phrenological principles, as well as introducing an entirely new section on "Spectral illusions" that had not been there in the first edition of 1830 . Like Hibbert, he suggested that "the brain be brought by internal causes to a degree of excitement, which, in general, is the result only of external impressions, ideas not less vivid than sensations ensue; and the individual has the same consciousness as if an impression were transmitted from an actual object through the senses." 62 However, he also defended the phrenological interpretation of apparitions as being the product of an overdeveloped faculty of Wonder. ${ }^{63}$

\footnotetext{
${ }^{60}$ [Combe], "Dr Hibbert on the Philosophy of Apparitions," 550.

${ }^{61}$ For a fascinating study of the development of Macnish's ideas, see Coyer, "Phrenological dreamer," 1-11.

${ }^{62}$ Robert Macnish, The Philosophy of Sleep, 2nd edn (Glasgow: W.R. M'Phun, 1834), 243.

${ }^{63}$ Macnish, Philosophy of Sleep, 244.
} 


\section{Attitudes to the supernatural and the religious schism in Scotland}

Both Brownian and phrenological theories of apparitions should be viewed in the context of the ongoing cultural struggle between Moderate and Evangelical Parties in the Established Church that ultimately led to the Disruption of 1843, breaking apart the Church of Scotland and leading to the secession of the Free Church of Scotland. For many Evangelicals in particular the question of apparitions was intimately tied up with the question of the nature of the Deity. Was he the God of the Moderates, who acted through secondary causes and whose works were accessible to human reason, or the more arbitrary God of the Evangelicals, whose power was exerted directly and often through supernatural agency?

For Hibbert, the age of miracles, when God suspended the laws of nature rather than relying solely on regular, secondary causes, was long past, and with it any possibility that God would allow the intervention of spiritual entities in the material world:

as we are not warranted, for many reasons, which may be defended on scriptural grounds, to suppose that any direct converse with good or evil spirits, connected either with the Jewish or the Christian dispensation, has extended beyond the Apostolic age, there will be no hesitation on my part to proceed on the hypothesis, that all the subsequent visitations of this nature which have been recorded, deserve a medical rather than a theological investigation. ${ }^{64}$

\footnotetext{
${ }^{64}$ Hibbert, Philosophy of Apparitions, 137.
} 
Macnish makes very much the same point, writing that God "appears no more in visions, to warn, to instruct, to solace. He speaks not in thunder upon Mount Sinai, or moves before His people as a pillar of fire, or arrests the laws of nature in their behalf. Earth has become more remote from heaven than in those favoured times, and is now, in all cases, governed by fundamental laws originally made by God for its regulation." ${ }^{\prime 65}$ If there had ever been an age of miracles, it was over now, and all phenomena were amenable to rational explanation. Walter Scott concurred; while it could not be known exactly when "miraculous power was withdrawn from the Church [...] few Protestants are disposed to bring it down beneath the accession of Constantine, when the Christian religion was fully established in supremacy."66

Both Brownians and phrenologists tended to see belief in the supernatural as a product of religious enthusiasm, whether Catholic or Presbyterian. Macnish is particularly scathing in his denunciation of such manifestations of superstition: "The visions of angels, and the communications from above, with which religious enthusiasts are often impressed, arise from the operation of spectral illusions. They see forms and hear sounds which have no existence; and, believing in the reality of such impressions, consider themselves highly favoured by the Almighty." ${ }^{\prime 67}$ He went on the explicitly suggest that the Covenanters of the late seventeenth century, who many Evangelicals saw as their spiritual forebears, were fanatics whose religious experiences were delusionary: "Nothing was more common than for the Covenanter by the lonely hill side to have what he supposed a special message from God, and even to see the angel who brought it standing before him." ${ }^{68}$ Scott in his Letters on Demonology likewise talks of the

\footnotetext{
${ }^{65}$ Robert Macnish, Philosophy of Sleep, 103.

${ }^{66}$ Scott, Letters on Demonology, 72-3.

${ }^{67}$ Macnish, Philosophy of Sleep, 246-7.

${ }^{68}$ Macnish, Philosophy of Sleep, 247.
} 
belief in ghosts as among "the numberless extravagances of the Scottish Dissenters of the 17th century, now canonized in a lump by those who view them in the general light of enemies to prelacy." ${ }^{69}$ Such remarks were sure to arouse the hostility of the Evangelical Party. Any attempt to explain supernatural phenomena naturalistically or deny the power of God to perform miracles in the modern world was bound to generate a reaction from those who faith was bound up with a belief in the power of God to transcend the laws of nature as and when he saw fit. The Scottish Presbyterian evangelicals were operating squarely within a voluntarist tradition that saw omnipotence as the predominant attribute of God; any suggestion that God's will was constrained by natural law was to be fiercely resisted. In the deity of the Moderates they saw, in the words of John Henry, "a God who is hidebound by the laws of logic, whose omnipotence is compromised by the need to obey the same ineluctable laws as mankind, whether laws of logic, of nature, or of morals." ${ }^{, 70}$ Given the emphasis placed by Hibbert on the impossibility of supernatural agency in the world and his denial of the role of any but secondary causes, it was inevitable that his theory would encounter hostility from some evangelical commentators. In an unpublished letter to an unknown recipient quoted in Mary Clementina Hibbert Ware's biography of her father-in-law, Hibbert wrote of the opposition his book encountered from this quarter:

The Rev. Andrew Thompson [Andrew Mitchell Thomson (1779-1831)], the editor of the Christian Instructor, says I have written a dangerous book; and he absolutely, in this spirit, advocates the existence of ghosts. But carefully as I thought I had prevented my

\footnotetext{
${ }^{69}$ Scott, Letters on Demonology, 83.

${ }^{70}$ John Henry, "Palaeontology and Theodicy: Religion, Politics and the Asterolepis of Stromness," in Michael Shortland (ed), Hugh Miller and the Controversies of Victorian Science (Oxford: Oxford University Press, 1996): $151-70,160$.
} 
arguments from interfering in the smallest degree with theological views, it is impossible to please some of those intolerant Christians, who falsely arrogate to themselves the name of Evangelical. ${ }^{71}$

Hibbert clearly associated the acceptance of supernatural explanations of apparitions with the excesses of religious enthusiasm. It was therefore no surprise that he also saw superstitious beliefs as a source of the imagery commonly experienced by those who were prone to spectral illusions and wrote that it was: "[n]o wonder then, that when, from some morbid state of the system, the superstitious have been rendered liable to spectral impressions, the figures of saints, angels, ghosts, or demons, should, above all other shapes, have formed the subject of their waking visions."72 Such views earned his book the blistering review it received from Thomson. Writing under the pseudonym "S.," he wrote that Hibbert's theory supported the view that "the visions of the Patriarchs, Prophets, and Apostles, and even the miracles of the blessed Lord himself, are nothing better than the illusions of the diseased, of the drunkard, and of the insane." 73 Evangelicals were more than ready to see spiritual entities, both good and evil, at work in the world. Nonetheless, not all Evangelicals were hostile to Hibbert's theory. Despite his Evangelical allegiances, Brewster was happy to accept Hibbert's theory and even to further elaborate it. A man of science himself, he was more open to a scientific explanation of apparitions than some of his Evangelical brethren. As he later wrote in a review of William Whewell's Bridgewater Treatise: “the highest demands of truth and the best interests of mankind, are invariably sacrificed when religion is intruded into questions of science and civil

\footnotetext{
${ }^{71}$ Samuel Hibbert, unpublished letter to an unnamed friend, quoted in Gordon, Life and Correspondence of the Late Samuel Hibbert Ware, 353.

${ }^{72}$ Hibbert, Philosophy of Apparitions, 133-4.

73 "S.," "Remarks on Dr Hibbert's Philosophy of Apparitions," Edinburgh Christian Instructor 23:11 (1824): 724730,730 .
} 
policy."74 Unlike Thomson, his friend and fellow Evangelical, Brewster did not consider that Hibbert's naturalistic explanation for apparitions presented a serious challenge to God's power to suspend the laws of nature. However, he did add a warning in a footnote to his Letters on Natural Magic against assuming natural causes for "those events in sacred history which Christians cannot but regard as the result of divine agency." 75

Like Hibbert, Combe saw religious visions as a product of a derangement of the nervous system. In his System of Phrenology he describes a case observed by Gall of "a fanatic, who believed that JESUS CHRIST, surrounded by a brilliant light, as if a million of suns had combined their splendours, had appeared to him to reveal the true religion." ${ }^{, 76}$ He goes on to quote Spurzheim as suggesting that "the religious sects of Swedenborgians, Methodists, Quakers, and many others, particularly demonstrate" an over-active organ of Wonder. ${ }^{77}$ Evangelicals, who placed so much emphasis on intense, personal religious experience might well have asked themselves if Combe would interpret these too as merely the consequences of an overdeveloped or morbidly overstimulated organ of Wonder. As the author of a letter to the Evangelical periodical the Edinburgh Christian Instructor wrote using the pseudonym "J.H." in 1820, if the phrenologists were correct then, try as he may, a person who "wants the organ of veneration" cannot be devout. ${ }^{78}$ This seemed to open the door to an insidious form of fatalism that undermined the role of the will in choosing the path to redemption. Like Hibbert, Combe was to encounter hostility from some evangelicals, including those who formed an important faction within the Edinburgh

\footnotetext{
${ }_{74}^{74}$ [Brewster, David], Review of William Buckland, Geology and Mineralogy, Edinburgh Review 65 (1837): 1-39, 4.

${ }^{75}$ Brewster, Letters on Natural Magic, 6.

${ }^{76}$ Combe, A System of Phrenology, 227-8.

${ }^{77}$ Johann Gaspar Spurzheim, quoted in Combe, System of Phrenology, 230. The quote come from Spurzheim, The Physiognomical System of Drs. Gall and Spurzheim, 206.

78 "J.H.," "The system of Gall and Spurzheim opposed," Edinburgh Christian Instructor 19(4) (1820): 219-23, 222 3.
} 
Phrenological Society. These included a number of leading phrenological figures who until the mid-1820s had been close associates of Combe, including David Welsh (1793-1845) and William Scott (1782-1841). The publication of the Constitution of Man in 1828 was the final straw for this influential group, who left the Society soon after, leaving it entirely in the hands of Combe's faction. The relationship of the evangelicals with phrenology was complex and changed over time. It is significant that The Edinburgh Christian Instructor published nine letters on phrenology between February 1820 and June 1824, all but two of which supported the new science. While there was a veritable evangelical campaign against Combe from 1828 onwards, before this date many evangelicals saw absolutely no contradiction between the doctrines of phrenology and their religious faith and a significant number continued to believe in its basic tenets even after the break with Combe.

\section{Conclusion}

Both Hibbert and the phrenologists shared an essentially similar approach to the problem of apparitions. Both drew heavily from the tradition of Scottish sensationalist philosophy. The fundamental difference in their theories was the interposition by the phrenologist of the faculties between the mind and the perceived phenomena, making apparitions the product of the overdevelopment of certain faculties as well as an altered physiological state. However, both saw apparitions as being essentially rooted in physiological disorder. They also maintained a courteous and respectful relationship in their personal dealings and correspondence, although Combe was clearly irked by Hibbert's failure to embrace phrenology. Despite these evident similarities in their theories, they belonged to opposing camps in the debate on phrenology. 
Hibbert sided with the University and medical establishment in his rejection of phrenology, while Combe was the recognized leader of the younger medical men and other professionals who flocked to the new science of the mind. They were therefore separated less by the incommensurability of their theories than by their adherence to different ideological camps. As a result, while Hibbert's work was generally well received by the moderate literati and reviled by some in evangelical circles for his dismissal of supernatural experiences, Combe's thoughts on the subject were dismissed by phrenological sceptics of all persuasions along with the rest of his doctrine of the faculties.

The advocates of naturalistic explanations of apparitions were often keen to brand supernatural beliefs as blind superstition and relegate them to the dark, pre-Enlightenment days of Scottish history. Nonetheless, belief in ghosts never died altogether, and interest in the supernatural was to see a dramatic mid-century resurgence. In both religious and secular culture the supernatural was in the ascendant in the 1830s and 1840s. In the religious sphere this anti-rationalist tendency manifested itself in the continuing rise of the Evangelicals and their voluntarist theology. For them, God constantly maintained the laws of nature in operation by an act of divine will, so that a miracle or other suspension of natural law should be no more surprising to the believer than the everyday maintenance of those laws. Laws of nature only existed because God generally chose to be consistent in his actions. In the secular domain the middle decades of the nineteenth century also saw the rise of a vibrant spiritualist movement, dedicated to proving the reality of supernatural phenomena. ${ }^{79}$ Nonetheless, Scottish evangelical opinion was not monolithic, and

\footnotetext{
${ }^{79}$ See, for example, Janet Oppenheim, The Other World: Spiritualism and Psychical Research in England, 18501914 (Cambridge: Cambridge University Press, 1985).
} 
the examples of Brewster and the Evangelical phrenologists show that some were prepared to go much further in accommodating naturalistic theories than others.

Walter E. Houghton has written of "the pain of doubt and the intense will to believe" of middleclass Victorians. ${ }^{80}$ The "Victorian frame of mind" he described so eloquently was a product of a profound crisis of faith rooted in the collapse of Enlightenment belief in a rationally comprehensible natural and social order governed by divine providence. Instead of a force for universal progress, the rational and speculative thought of the Enlightenment seemed to have led only to the disaster of the French Revolution and the threat of complete social breakdown. The consequent reaction of the middle classes was a retreat to the security of tradition and authority. In this climate, the fascination with the supernatural and the readiness to embrace dogmatic, antiintellectual belief systems were very much signs of the times. These developments were still nascent in the early decades of the century. By challenging supernatural explanations of apparitions, Hibbert, Combe and other like-minded thinkers reaffirmed the power of reason to banish the shadows of superstition, thereby defending the Enlightenment values to which they were heirs. By reducing apparitions to the status of a medical phenomenon they were in effect reaffirming their faith in the reality of a benevolent natural order, governed by natural law in the service of divine providence rather than at the mercy of the erratic, vengeful God of the Evangelicals.

\footnotetext{
${ }^{80}$ Walter E. Houghton, The Victorian Frame of Mind, 1830-1870 (New Haven, CT: Yale University Press, 1957), 154.
} 